\title{
Level of undertriage in a well established Trauma Registry in Denmark
}

\author{
Anne Cathrine Haug ${ }^{*}$, Thomas Wilson, Morten Schultz Larsen, Jens Lauritsen \\ From Danish Society for Emergency Medicine: Research Symposium 2010 \\ Roskilde, Denmark. 20-21 May 2010
}

\section{Background}

It is universally accepted that patients suffering major trauma, may need a high level of immediate care on arrival at hospital to secure the best outcome. Triage is the allocation of injured patients to a suitable treatment level, and is also at our hospital based on a set of criteria which is based on pre-hospital values and findings. The trauma registry at Odense University Hospital (OUH), which registers the hospitals' admitted trauma patients, was established in 1996. Previously no studies have been done for this registry. Our aim was to assess the amount and character of undertriage and estimate the level of overtriage.

\section{Methods}

Retrospective analysis of data collected from OUHs list of patients admitted with ICD S- and T diagnoses in 2007 . Inclusion criteria were ISS $>15$, treated in intensive care unit $>2$ days, dead within 30 days, or proximal penetrating injury. Overtriage was identified from the trauma registry of patients received by the trauma team, where the severely injured patient was defined as having ISS $>15$.

\section{Results}

Potential undertriage if all inclusion criteria were followed was $22 \%$. Undertriage if only ISS-score is used is $10 \%$. Women had a higher risk of undertriage than men, and undertriaged patients were significantly older than correctly triaged patients. We discovered a high frequency of falls from low heights in undertriaged patients. 628 patients were admitted by the trauma team, with an overtriage of $86 \%$ assessed by ISS-score.

\footnotetext{
* Correspondence: annecathrine_haug@hotmail.com Accident Analysis Group, Odense University Hospital, Sdr. Boulevard 29, DK5000 Odense C, Denmark
}

\section{Conclusion}

We found an undertriage proportion comparable to similar studies. Elderly patients and women had a higher risk of undertriage, which also has been found in other studies. We suggest that research should be concentrated on the reasons for this. We also found that if all inclusion criteria are used uncritically, it might overestimate undertriage. However, we suggest further research into whether the elderly and comorbid could reap benefit from medical participation early in the treatment process of even minor trauma.

Published: 17 September 2010

doi:10.1186/1757-7241-18-S1-P20

Cite this article as: Haug et al:: Level of undertriage in a well established Trauma Registry in Denmark. Scandinavian Journal of Trauma, Resuscitation and Emergency Medicine 2010 18(Suppl 1):P20.

\section{Submit your next manuscript to BioMed Central and take full advantage of: \\ - Convenient online submission \\ - Thorough peer review \\ - No space constraints or color figure charges \\ - Immediate publication on acceptance \\ - Inclusion in PubMed, CAS, Scopus and Google Scholar \\ - Research which is freely available for redistribution \\ Submit your manuscript at www.biomedcentral.com/submit}

